\title{
PMIP Ocean - Understanding changes since the Last Glacial Maximum
}

\author{
Andreas Schmittner', S.P. Harrison², A.E. Carlson', A.C. Mix, M. Kageyama ${ }^{3}$ and Michal Kucera ${ }^{4}$ \\ Corvallis, USA, 4-6 December 2013
}

More than 40 scientists met in Corvallis, Oregon, to discuss how ocean data can be better used to evaluate results from the Paleoclimate Model Intercomparison Project (PMIP). Focus was on the Last Glacial Maximum (LGM; 19-23 ka ago) and the Mid-Holocene ( $\mathrm{MH} ; 6$ ka ago). However, many talks went beyond these time periods and showed new and exciting paleodata from the deglacial transition from the LGM to the Holocene, and model simulations. The idea of a new community experiment for transient modeling of the deglaciation in the next PMIP was discussed with enthusiasm.

Talks and discussions during the first day focused on methods of model-data comparison (Fig. 1), quantifying uncertainty and ocean temperature reconstructions, particularly from the tropics (including a report from a one-day preluding workshop on tropical sea-surface temperatures). Systematic differences between various proxies (e.g. alkenones, Mg/ $\mathrm{Ca}, \mathrm{TEX} 86$, foraminifera faunal assemblages) were diagnosed and new methods of quantifying uncertainties and forward modeling of individual foraminifera species were presented. It appears likely that the seasonal and vertical attribution of sea surface temperature reconstructions is a major reason for discrepancy among different proxies. Contrary to previous interpretation, it seems that in some cases foraminifera assemblages do record shallow subsurface temperatures rather than surface temperatures. Temperatures at the subsurface may also show larger climate signals than at the surface in some areas, as suggested by model simulations.

The second day focused on the deep ocean. Stable carbon isotopes $\left(\delta^{13} \mathrm{C}\right)$ and radiocarbon $\left(\triangle^{14} C\right)$ provide important constraints on deep-ocean circulation and carbon cycling. Inverse model solutions using $\delta^{13} \mathrm{C}$ data indicate that the Atlantic Meridional Overturning Circulation (AMOC) during the LGM may not have been significantly different from today. Another presentation highlighted that in model simulations of the LGM, ocean circulation requires thousands of years to equilibrate. This raised the issue of whether the LGM (or in fact any time interval) can be considered to ever be in an equilibrium state, either for models or data reconstructions. Although radiocarbon is perhaps the most direct proxy for deep ocean circulation, independent dating is needed to allow its interpretation as a circulation tracer. The assumption of constant surface reservoir ages made in many previous studies may in some cases not be true, at least during the deglaciation. Nevertheless, new radiocarbon data from the North Pacific and Southern Ocean advance our understanding of deep
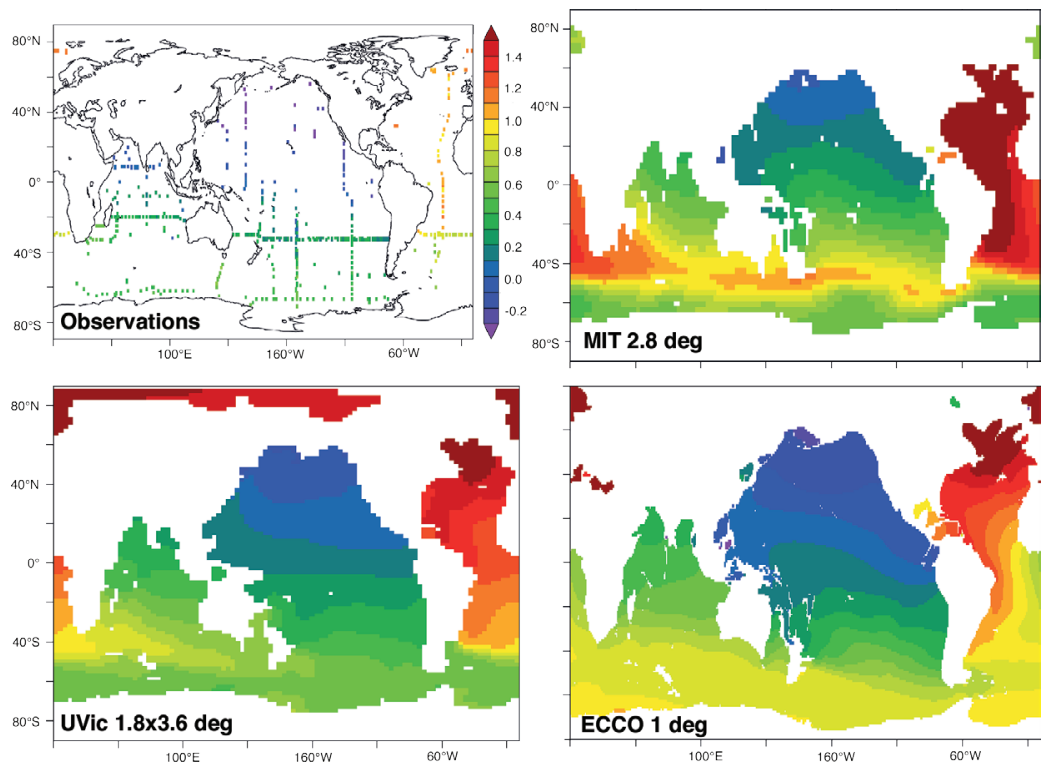

Figure 1: Comparison of deep $(2 \mathrm{~km})$ ocean $\delta^{13} \mathrm{C}_{\mathrm{DIC}}$ distributions in modern observations (top left) and three different circulation models calculated using the same underlying biogeochemistry model (MOBI; Schmittner et al. 2013) and transport tracer matrix method (Khatiwala et al. 2005). The model simulations do not account for the anthropogenic rise in atmospheric $\delta^{13} \mathrm{C}$. Note the effect of higher resolution $\left(1^{\circ} \times 1^{\circ} \mathrm{MIT}\right.$-ECCO lower right) on the simulation of the western boundary current in the Atlantic compared with the coarser resolution models $\left(2.8^{\circ} \times 2.8^{\circ} \mathrm{MIT}\right.$ upper right and $1.8^{\circ} \times 3.6^{\circ}$ UVic lower left). PMIP3 LGM simulations using this offline method of calculating tracer distributions will be used in the future to predict isotope distributions for comparison with paleo data from ocean sediments. ocean circulation changes during the LGM and deglacial intervals.

Modeling studies highlighted the role of Laurentide ice-sheet topography in affecting global-mean LGM climate, model biases in the Southern Ocean for AMOC LGM simulations, and uncertainties in physical and biological processes in reproducing carbon cycling in the ocean.

During the last day, the potential for focused studies of past warm periods and new approaches to community databases were discussed. One presentation argued that an unfavorable signal-to-uncertainty ratio in the currently available sea surface temperature reconstructions prevents the use of $\mathrm{MH}$ data in constraining model simulations. Model simulations of the Miocene considering changes in the Antarctic ice sheet were also presented.

Databases are essential for the efficient creation of syntheses and for making paleoceanographic data more accessible. Two new approaches were introduced: one web based system and one offline tool, both of which can be expected to become available to the community in 2014 .

The workshop proceeded with discussions in breakout groups on data reporting standards, model-data comparison, and an outline for new PMIP simulations of the deglacial. A document recommending paleoceanographic data reporting standards has been started and will be further developed through PAGES. Another document outlining the discussions of the proposed new deglacial PMIP simulation was started and will be presented to the wider PMIP community at the upcoming PMIP3 conference in May 2014. This workshop was co-sponsored by the US NSF, PAGES, and INQUA. The meeting program and all of the abstracts can be found at:

http://people.oregonstate.edu/ schmita2/

Projects/PMIP_LGM_C13/PMIP_ocean_WS.html

\section{AFFILIATIONS}

${ }^{1}$ College of Earth, Ocean, and Atmsopheric Sciences,

Oregon State University, Corvallis, USA

${ }^{2}$ Centre for Past Climate Change, University of Reading,

UK and Department of Biological Sciences, Macquarie University, Sydney, Australia

${ }^{3}$ Laboratoire des Sciences du Climat et de l'Envi-

ronnement/IPSL, Gif-sur-Yvette, France

${ }^{4}$ Center for Marine Environmental Sciences, University of Bremen, Germany

CONTACT

Andreas Schmittner: aschmitt@coas.oregonstate.edu

REFERENCES

Khatiwala S et al. (2005) Ocean Model 9: 51-69

Schmittner A et al. (2013) Biogeosciences 10: 5793-5816 